\title{
A RELAÇÃO ENTRE OS PARTICIPANTES NO QUADRO BATE-PAPO DO PROGRAMA VIDA E SAÚDE (RBSTV/RS)*
}

\author{
Najara Ferrari Pinheiro \\ Centro Universitário Franciscano \\ Santa Maria, Rio Grande do Sul, Brasil
}

\begin{abstract}
Resumo: O programa Vida e Saúde da RBSTV/RS, no processo de popularização da ciência, apresenta um quadro denominado Batepapo, em que a editora-chefe/apresentadora do programa entrevista convidados combinando características da conversa informal com a da entrevista temática e dialogal. Neste artigo discuto, com base na Análise Crítica do Discurso, associada à Análise de Discurso Multimodal e à noção de tato, a relação entre os participantes, a partir da análise do Bate-papo como um formato de entrevista, com práticas específicas que envolvem as linguagens sonora, verbal e visual. Os resultados mostram que no Bate-papo os participantes dialogam entre si, procurando manter um tom informal, evidenciado pela interação face a face. Nesse tom, os participantes dizem e redizem as informações, a fim de simplificá-las, em um processo de recontextualização que pode até mudar o significado da linguagem técnica para a linguagem comum, linguagem que se aproxima daquela utilizada no cotidiano dos telespectadores.

Palavras-chave: Bate-papo. Entrevista. Popularização da ciência. Televisão. Recontextualização.
\end{abstract}

\footnotetext{
* Versão prévia deste artigo, focalizando gêneros e formatos, foi apresentada no SBPJor: Associação Brasileira de Pesquisadores em Jornalismo - $10^{\circ}$ Encontro Nacional de Pesquisadores em Jornalismo. Curitiba - Pontifícia Universidade Católica do Paraná Novembro de 2012. Uma versão revista e ampliada, com ajustes relativos à discussão sobre gêneros discursivos, fará parte do livro Gêneros: um diálogo entre comunicação $e$ Linguística Aplicada, organizado por Lia Seixas (UFBA) e Najara Ferrari Pinheiro (Centro Universitário Franciscano)

** Professor Adjunto. Estágio pós-doutorado júnior realizado no LABLER/PPGL/UFSM/CNPq; Pesquisa desenvolvida com apoio do CNPq, processo nº70.261/2010-2 (Edital Universal MCT/CNPq 14/2010 - Faixa A); bolsa Pós-Doutorado Júnior - processo nº152.344/2010-1. Email: najaraferrari@gmail.com.
} 


\section{PROGRAMA VIDA E SAÚDE E A POPULARIZAÇÃO DA CIÊNCIA: SITUANDO A DISCUSSÃO}

O programa Vida e Saúde, da RBSTV/RS, está no ar há nove anos e aborda com prioridade as temáticas relativas à saúde, bem-estar e qualidade de vida. Tais temáticas são discutidas e apresentadas nos programas veiculados na grade da emissora, aos sábados, entre $8 \mathrm{~h} 05 \mathrm{~min}$ e $8 \mathrm{~h} 30 \mathrm{~min}$. A RBS TV é uma televisão regional, porque forma uma rede que, além de 'falar' com a região Sul, região de sua abrangência, articula-se e dialoga com as outras regiões do Brasil, por meio da Rede Globo. Considerando tais aspectos, a investigação se concentra no programa Vida e Saúde da RBSTV/RS.

Esse programa tem 25 minutos de duração e, na grade de programação da emissora, está entre um programa de circulação nacional Ação (Globo TV) - e um programa da TV Regional (RBS) - Anonymus Gourmet. Considero, nesta pesquisa, o perfil da audiência na praça de Porto Alegre. Os índices de audiência correspondem a 11,6\% de audiência domiciliar e $45,2 \%$ de share ${ }^{1}$. A seleção de tais dados implica esboçar um perfil dos telespectadores do programa na cidade que, por sua diversidade, em tese, representa a população do estado do Rio Grande do Sul.

O programa é apresentado por Laura Medina e Isabel Ferrari (substituída no período de licença maternidade por Evelyn Bastos). A equipe também é formada pela repórter Flávia Marroni, pelo cinegrafista Paulo Vitor e pelo operador de áudio Paulo Sérgio. A edição de imagens é de Gerson Cordeiro e a finalização, de Rafael Peçanha. Iraci Lopes é o responsável pela sonorização. Em 2012, a equipe estava formada por Laura Medina (Editora-chefe e apresentadora), Isabel Ferrari (apresentadora) e Flavia Marroni (repórter).

$\mathrm{Na}$ sua organização, veicula entrevistas e reportagens sobre saúde, nutrição, atividade física, beleza, comportamento e terapias alternativas. Essas informações foram encontradas em site específico ${ }^{2}$, no portal Clicrbs,

\footnotetext{
${ }^{1}$ Os dados apresentados referem-se ao Vida e Saúde na praça de Porto Alegre em 2008. Disponível em: <http://www.clicrbs.com.br/pdf/6402640.pdf>. Acesso em: 21 abr. 2011.

${ }^{2}$ Para informações adicionais sobre o programa, acesse a página "Saiba Mais". Disponível em: <http://www.clicrbs.com.br/especial/rs/rbstvrs/conteudo,936,7583,Vida-e-Saude-Sobreo-programa.html> Acesso em 21 abr. 2011.
} 
em pesquisa realizada em 2011. Desde fevereiro de 2012, as informações estão com outra configuração, inseridas no portal G1, da Rede Globo ${ }^{3}$. A participação no share revela que, na praça de Porto Alegre, o maior número de telespectadores é do sexo feminino (58,9\%), com idade entre 25 e 49 $\operatorname{anos}(42,4 \%)$, pertencentes à classe $\mathrm{C}(57,1 \%)$.

Como pode ser observado no corpus compreendido de programas gravados entre agosto de 2010 e março de 2011, essa produção congrega vários assuntos, podendo ser entendida como um programa de variedades ou de entretenimento, o qual privilegia um foco: a saúde. Considerando seu nome e seu conteúdo, tende-se a pensar em uma produção especializada em saúde, pois difere de outros programas de variedades da televisão brasileira. No entanto, as discussões não se restringem apenas ao tema saúde, mas todas convergem e se aproximam do ideal de saúde, proposto pela Organização Mundial de Saúde (OMS): "Saúde é o estado do mais completo bem-estar físico, mental e social e não apenas a ausência de enfermidade". A reflexão que deve ser feita está relacionada com a ideia de saúde e "uma vida plena, sem privações".

O Vida e Saúde pode ser reconhecido com um fenômeno do infotainment, neologismo que, segundo Gomes (2009, p.1), "traduz o embaralhamento de fronteiras entre informação e entretenimento, tem ocupado boa parte da energia produtiva de profissionais e investigadores de algum modo ligados à Cultura Midiática". Para a pesquisadora, nesse embaralhamento de fronteiras e no distanciamento de gêneros televisivos conhecidos, está o infotainment, agora não mais um fenômeno, mas "uma estratégia midiática que serve para classificar os produtos televisivos que não se enquadram muito claramente em nenhum dos gêneros que conhecemos" (GOMES, 2009, p.11).

Newcomb (2010), ao discutir o diálogo na televisão, refere-se à observação de Bakhtin (1992) sobre a coexistência de gêneros variados. Para Newcomb (2010, p. 375), "os gêneros variados coexistem juntos no tempo e ele focalizou ainda mais especificamente os modos pelos quais o romance interpola outros gêneros, engolindo a carta, o discurso, o ensaio,

\footnotetext{
${ }^{3}$ Os dados atuais podem ser encontrados no endereço $<$ http://redeglobo.globo.com/rs/rbstvrs/ noticia/2011/12/vida-e-saude.html>. Acesso 10 ago. 2012.
} 
moldando-se com a reportagem, a sátira e, o que é mais importante, com a paródia". Interessa aqui destacar esse fenômeno da interpolação dos gêneros já evidenciada por Bakhtin. Dito de outro modo: a mescla, o embaralhamento de fronteiras ou a hibridação (FAIRCLOUGH, 2001) são modos de dizer que os gêneros se interpolam e uns engolem os outros, tornando-se distintos de seus originais, mas guardando resquícios de sua história.

Por essa via, passo a analisar os programas como um híbrido que tem no infotainment sua âncora. Dessa forma, observo nesse programa o que Newcomb (2010, p. 374) afirma sobre o texto televisivo: "a evolução dos gêneros de televisão nos fornece uma espécie de arqueologia do universo dialógico da televisão".

\section{ANÁLISE CRÍTICA DO DISCURSO E ANÁLISE DE DISCURSO MULTIMODAL: FUNDAMENTOS PARA ANÁLISE}

A perspectiva tridimensional de discurso, proposta por Fairclough (2001), como uma concepção teórico-metodológica para a Análise Crítica do Discurso, subsidia esta discussão. Nessa abordagem, o autor, seguindo o percurso da teoria social do discurso, define discurso como representação de mundo; "diferentes discursos são diferentes maneiras de representar aspectos do mundo" (FAIRCLOUGH, 2003, p.215).

O discurso contribui para a construção de (a) 'posições de sujeito' ou 'identidades sociais'; (b) relações sociais; e (c) sistemas de conhecimento e crença. Tais efeitos, segundo Fairclough (2001, p. 91), correspondem a três dimensões de sentido ou funções da linguagem, as quais são relacionadas às metafunções de Halliday (1985): (a) a função identitária corresponde à maneira como as identidades sociais são estabelecidas, negociadas e fortalecidas no discurso; (b) a função relacional refere-se aos modos como as relações sociais são instituídas e negociadas no discurso; e (c) a função ideacional relaciona-se com as maneiras de significar o mundo, seus processos, suas entidades e relações.

Na proposta de análise, a cada dimensão estão associadas categorias analíticas: ao texto, as categorias de vocabulário, gramática, coesão e 
estrutura textual; às práticas discursivas, as categorias de produção, distribuição, consumo de textos, contexto, força, coerência e intertextualidade; às práticas sociais, as categorias de ideologia (sentidos, pressuposições e metáforas) e hegemonia (orientações políticas, econômicas, culturais e ideológicas). O texto, nessa perspectiva, é a base para a análise das práticas sociais.

A prática discursiva que envolve produção, distribuição e consumo, contexto e força, além de coerência e intertextualidade, varia de acordo com os fatores sociais e em função dos diferentes tipos de discurso (FAIRCLOUGH, 2001, p. 107). Na análise do texto televisivo, um texto que depende de rotinas de produção complexas - pauta, cenários, gravações e edições -, há que se considerar a natureza coletiva de sua produção. Trata-se de processo que ocorre em diferentes etapas, que iniciam com a reunião de pauta e finalizam com a edição. A cada uma dessas etapas há participantes específicos implicados. Já a distribuição envolve o meio técnico e depende muito menos de participantes e mais das rotinas do meio (televisão). A distribuição é simples, embora atinja um público (ou audiência) significativo em termos de índices.

O consumo do texto televisivo, em função das práticas sociais contemporâneas, é coletivo, ou seja, sua distribuição em um meio de comunicação atinge um grande número de telespectadores. Vale destacar que, mesmo sendo fundado na imagem, na linguagem visual, o texto televisivo se constitui na relação com a linguagem oral. Reportando a estudos já realizados, destaquei essa supremacia do sonoro, em relação ao visual (PINHEIRO, 2004, p. 42). Retoma-se, daquela discussão, a afirmação de Machado (2005):

apesar de os avanços tecnológicos permitirem um aprimoramento na produção gráfica, a televisão é um meio bem pouco visual e, como herdeira direta do rádio, ainda se funda no discurso oral e faz da palavra a sua matéria-prima principal. Como a TV privilegia a palavra, então, a maior parte de seus programas prioriza a oralidade, estruturando-se a partir da imagem prototípica de uma talking head (cabeça falante), seja na figura de um entrevistador, de um âncora, de um apresentador (como nos magazines femininos) ou de um entrevistado nos talk shows. (PINHEIRO, 2004, p. 42). 
A entrevista ou o Bate-papo, quadro do programa Vida e Saúde analisado neste artigo, evidencia o privilégio da oralidade, por isso a investigação considera as linguagens visual e sonora, na análise das práticas discursivas.

O texto televisivo e suas múltiplas linguagens exigem que se associe e se analise os produtos ou textos televisivos pela ótica da multimodalidade. Diante dessa demanda, associa-se para a investigação os fundamentos da Análise de Discurso Multimodal (ADM) (O'HALLORAN, 2011). A ADM torna-se importante para a análise dos textos televisivos, pois, como um paradigma emergente nos estudos do discurso, estende os estudos da linguagem para os estudos da linguagem em combinação com outros recursos, tais como imagens, símbolos científicos, gestos, ações, música e sons - em síntese, as linguagens visual, sonora e verbal, características da produção televisual.

Com apoio em Halliday (1978), O'Halloran (2011) afirma que os recursos semióticos são sistemas de significados que constituem a realidade da cultura. $\mathrm{O}$ medium é o meio através do qual o fenômeno multimodal se materializa (jornal, televisão, computador).

Na perspectiva de Jewitt (2009, p. 34), é necessário investigar os atores sociais e, nesse caso, o entrevistado e o entrevistador, observando/analisando gestos, olhar, movimento do corpo e layout, dentre outros modos, para "mediarem a interação num dado contexto". No caso da entrevista, ou do quadro Bate-papo no programa Vida e Saúde, é importante associar essa perspectiva para a análise, visto que ela contribui para evidenciar as regularidades das linguagens visual e sonora desse formato.

No desenho das regularidades do quadro Bate-papo, utiliza-se como critério para análise o enquadre, a distância e a posição (ver também KRESS; van LEEUWEN, 1996). Tais perspectivas, aliadas à Análise Crítica do Discurso, contribuem para se construir uma investigação sobre a relação dos participantes nesse quadro. Essa discussão será aprofundada na seção 4 .

A entrevista, segundo Fairclough (2001, p. 80), representa um gênero de objetivação e corresponde à técnica de objetivação. Essa objetivação, 
relacionada à entrevista formal, à entrevista terapêutica, por exemplo, é concebida pelo autor como aspectos da "ordem do discurso moderna". A entrevista, nessa ordem de discurso, revela os "modos de discurso que manipulam as pessoas como objetos, por um lado, e os modos de discurso que exploram e dão voz ao 'eu'" (FAIRCLOUGH, 2001, p. 80), por outro.

Para este artigo, interessa destacar os modos de discurso que exploram e dão voz ao eu. Nessa via, seguir os construtos de Lage (2001) sobre a entrevista contribui para interpretar o valor da entrevista na televisão. Para o autor, 'entrevista' é um termo ambíguo e pode tanto significar o diálogo com a fonte como a matéria publicada. Desambiguizando o termo, neste artigo, entrevista expressa o diálogo com a fonte.

Seguindo ainda a proposição de Lage (2001), a classificação das entrevistas está vinculada a tipos - ritual, temática, testemunhal e em profundidade (LAGE, 2001, p. 74-75) - e a circunstâncias - ocasional, confronto, coletiva e dialogal. Considera como a entrevista por excelência a dialogal. A partir dessa classificação, enfatiza-se a relação com os modos de dar voz ao eu.

O Bate-papo, como um espaço no programa Vida e Saúde, dá voz ao saber especializado, a fim de popularizar o conhecimento científico. É uma relação entre participantes que envolve o saber especializado do eu (entrevistado) para o tu (telespectador), mediado pela entrevistadora.

\section{METODOLOGIA}

Entre os 21 programas gravados para a pesquisa, selecionei 3 quadros da seção Bate-papo para esta análise. Como critério de seleção, elenquei três variáveis: a temática, o cenário e os entrevistados. Para a análise do gênero, utilizei a tipologia de Lage (2001), já destacada anteriormente, procurando relacionar essa tipologia à noção de tato, que Stam (2010) retoma dos fundamentos de Bakhtin e atualiza para a análise de produtos televisivos. Também utilizou-se a ADM para investigar a relação das linguagens visual, sonora, gestual, verbal nos quadros analisados. A temática foi selecionada em função da pesquisa que é 
desenvolvida pela pesquisadora: saúde - processo de popularização da ciência. Contou para essa seleção o fato de vários quadros sobre o assunto terem sido apresentados em períodos muito próximos. Assim, para esta investigação, destaquei:

- A temática: Transtornos emocionais;

- O cenário: Sala de visitas e café/restaurante;

- As linguagens: sonora e visual;

- Os participantes: os entrevistados - Médicos psiquiatras; a entrevistadora- Editora/apresentadora.

\section{BATE-PAPO COM LAURA MEDINA}

4.1 A ENTREVISTA

O Vida e Saúde é dividido em blocos separados por intervalos comerciais ou breaks. Os 25 minutos de programa podem ser assim representados: Vinheta de abertura, abertura (cabeça do programa), vinheta de passagem, intervalo comercial, vinheta de início de bloco, reportagens e entrevistas, encerramento, vinheta de encerramento.

A sequência é a representação esquemática simplificada do programa. Os fragmentos não são aleatórios e replicam o movimento que ocorre nos 21 programas gravados, que constituem o corpus da pesquisa.

$\mathrm{Na}$ desconstrução de um dos programas (e todos se repetem), os gêneros predominantes, como se pode observar, são a reportagem e a entrevista. A entrevista, em seus variados formatos (ver LAGE, 2001), se interpola, nos termos de Bakhtin (2005), nas reportagens. No programa, há diferentes espaços para apresentação das reportagens, considerando também a presença de diferentes apresentadoras/repórteres em cenários específicos.

Nessa produção, muitas temáticas são tratadas, muitos assuntos são pauta de reportagens ou de entrevistas, na seção Bate-papo, e muitos cenários são utilizados para realizar essas produções. Um dos cenários frequentes é o Hotel Vila Ventura, localizado na cidade de Viamão/RS. As entrevistas ou bate-papo são, em geral, ambientadas em locais fechados como cafés, restaurantes, salas de visita ou sala de recepção/descanso de 
hotel (Hotel Vila Ventura). Esses ambientes, segundo Lage (2001), são característicos de entrevistas definidas como de tipo dialogal. A entrevista dialogal é

marcada com antecedência, reúne entrevistado e entrevistador em ambiente controlado - sentados, em geral, e, de preferência, sem a interferência de um aparato (como uma mesa de escritório) capaz de estabelecer hierarquia (quem se senta diante das gavetas da mesa assume, de certa forma, posição de mando). Entrevistador e entrevistado constroem o tom de sua conversa, que evolui a partir de questões propostas pelo primeiro, mas não se limitam a esses tópicos; permite-se o aprofundamento e detalhamento dos temas abordados. (LAGE, 2001, p. 77).

De acordo com o autor, essa característica refere-se à circunstância de realização da entrevista. Neste artigo, destaco o ambiente ou cenário como lugar importante para construir o tom (ou estilo) ${ }^{4}$ da entrevista, no quadro Bate-papo. O estilo, segundo Fairclough (2001, p.163), varia de acordo com o tipo de relação entre os participantes e pode ser classificado, entre outras maneiras, como formal, informal, oficial, íntimo, casual.

O tom, conforme proposto por Fairclough (2001), é associado, aqui, à noção de "tato" (STAM, 2010, p. 335), ou seja, "às maneiras pelas quais o poder modula os 'diálogos' televisivos e configura a sua 'representação"' (STAM, 2010, p. 335). Seguindo o autor, corrobora-se a ideia de que o tato pode ser analisado, em termos bakhtinianos, como um produto das relações entre os interlocutores (dentro e fora da tela), entre entrevistado-entrevistador-telespectador, da situação concreta da "conversação", e do agregado de relações sociais e dos horizontes ideológicos que permeiam o discurso (STAM, 2010, p. 335).

Essa modulação mais a relação entre entrevistado e entrevistadora, na entrevista dialogal (situação concreta de conversação), permite a observação relativa ao tato, visto que a conversa flui e não se limita às respostas do entrevistado e às perguntas do entrevistador. Não há um

\footnotetext{
${ }^{4}$ Para Fairclough (2001, p. 153), junto com a fala e a escrita, além da gramática, outros aspectos do evento discursivo estão representados; um desses aspectos é o tom no qual as coisas foram ditas.
} 
sistema totalmente ordenado com regras aparentes para troca ou tomada de turno $^{5}$; em alguns casos, entrevistador e entrevistado, no bate-papo, misturam suas falas, sobrepõem a palavra até que um se sobreponha, tome a palavra e organize a fala, seguindo a sua abordagem sobre o assunto. Isso ocorre no Bate-papo sobre ansiedade, quadro do programa Vida e Saúde, de 07.08.2010:

Exemplo. Laura (L): "quando que deixa de ser um comportamento natural e passa a ser um transtorno?"

Médico (M): "a gente tem como um critério diagnóstico a questão tanto da amplitude do sintoma quanto. quanto do período ... se a gente pensar assim que se manifesta por mais de seis meses de modo predominante da vida da pessoa ... ou seja a pessoa tem esse tipo de apreensão no peito . o coração dispara . sudorese . suor $=$

L: "sempre que surgir o problema ela tá tensa

M: "pro. pro ... ela ela cria o problema... vamos dizer assim é desproporcional...

No exemplo, a fala se sobrepõe e, após a breve observação de Laura Medina, o Médico-Psiquiatra Cláudio Martins segue explicando os sintomas da ansiedade. A própria imagem reflete essa sobreposição, essa fala concomitante (sublinhado na Figura 1). Os movimentos das mãos são indicativos de que tanto a entrevistadora quanto o entrevistado estão falando ao mesmo tempo. O olhar e o movimento do corpo/cabeça, ombros também são reveladores do acompanhamento das falas dos participantes e da consequente sobreposição de suas conversas nesse fragmento. Aqui, a contribuição da análise multimodal torna-se imprescindível. Para O'Halloran (2011), a ADM inclui a interação entre os participantes: a linguagem falada, os sistemas semióticos (incluindo o olhar, a postura corporal e o gesto) e os efeitos da gramática televisiva (incluindo o ângulo da câmera e o tempo de duração do quadro). Nesse exemplo, interessa

5 Troca ou tomada de turno: "realização organizacional colaborativa dos participantes baseada num conjunto simples de regras ordenadas" (FAIRCLOUGH, 2001, p. 192).

${ }^{6}$ Segui o modelo de normas de transcrição do Projeto de Cooperação Brasil-Portugal (CAPES/GRICES no 217/08), disponível em: http://www.concordancia.letras.ufrj.br/index.php?option=com_content $\& v i e w=$ article $\& i d=5$ 2\&Itemid $=58$ 
observar que a interação entre os participantes e a sobreposição das falas estão acompanhadas de características que incluem a postura corporal, gestos com as mãos, movimentos de cabeça. Tais elementos podem ser observados nos detalhes destacados por setas na Figura 1.

\section{Figura 1 - Laura Medina e Cláudio Martins no Bate-papo}

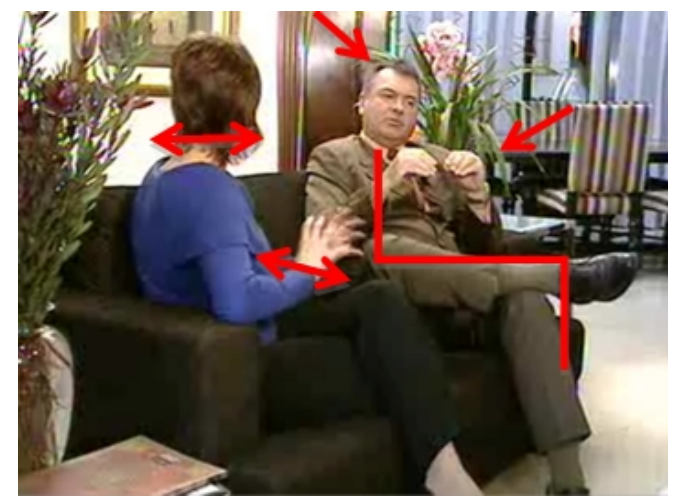

Fonte: Pesquisa

Os gestos com as mãos tornam-se significativos, pois, no frame selecionado, a fala está acompanhada desses gestos e o telespectador, que está fora da tela, percebe que há uma relação entre a fala da entrevistadora, a do entrevistado e os gestos realizados; as explicações são acompanhadas por gestos com as mãos; os gestos refletem o dizer.

O'Halloran (2011), seguindo a proposta de Tan (2005), reproduz a rede sistêmica para análise de vetores de olhar e recursos semióticos. Com base nesse sistema, para atingir os efeitos de sentido pretendidos na edição, a produção conjuga um trabalho (seleção, escolhas e cortes) que envolve os participantes - entrevistador e entrevistado -, a escolha de cenário, o movimento de câmeras e a seleção de planos. Nessa análise, a combinação dos recursos semióticos com os movimentos de câmera gera um efeito de sentido que combina o olhar do psiquiatra e seus gestos; os gestos da entrevistadora; a postura corporal e a fala dos participantes. Nesse exemplo, um frame recortado do programa, podemos observar que: 


\section{Médico}

a. o olhar dirige-se à entrevistadora (engajado);

b. os gestos com as mãos são contidos, os braços próximos ao corpo e os movimentos são voltados para o próprio corpo (reduz a distância em relação ao outro; exemplifica a fala);

c. a postura corporal, por meio do ângulo, revela informalidade, relaxamento, domínio em relação ao assunto, tensão mínima em relação à entrevistadora (engajado);

d. o jogo de câmera enquadra os participantes em planos de expressão ou de diálogo (REY, 2005) e a saliência da imagem coloca em evidência o médico, deixando a entrevistadora quase fora do enquadramento, tornando reconhecível o ambiente, mesmo que esse espaço apareça limitado;

e. o cenário selecionado é próprio para um bate-papo, uma entrevista dialogal (LAGE, 2001), realizado em ambiente controlado, sem interferência de aparatos (engajado).

As características destacadas aqui permitem interpretar o modo de relação do Médico, com base na ADM. Em relação à entrevistadora, a atitude do médico revela um alto grau de engajamento, visto que os recursos semióticos, no conjunto do frame selecionado, indicam a conexão entre entrevistador e entrevistado. Essa conexão é planejada pela produção a partir da escolha do cenário e da edição de cenas na pós-produção. É natural ou não intencional quando se trata da relação fala-olhar-gestos, pois tais atos nem sempre são regulados na organização da entrevista; o tom revela proximidade e informalidade na conversa, no bate-papo.

\section{Entrevistadora}

a. os gestos com as mãos são mais amplos e dirigem-se para o entrevistado (engajado);

b. a postura corporal, por meio do ângulo e do enquadramento, revela maior tensão, posição de controle e orientação do bate-papo, domínio deste e movimentos de ombros e cabeça durante a fala (engajado); 
c. o jogo de câmera enquadra a entrevistadora em primeiro plano (a câmera está posicionada lateralmente atrás da apresentadora), no entanto sua posição é de quase apagamento em relação ao cenário, visto que está quase fora de cena e fora do quadro.

A imagem congelada de um frame corresponde a frações de segundos de uma sequência de imagens contínuas na televisão. Essa percepção e análise com a imagem congelada pode dar apenas uma noção dos prováveis sentidos da imagem no texto televisivo. A sua potencialidade está relacionada aos efeitos e sentidos resultantes da soma das linguagens, ou seja, dos sons, dos movimentos, dos gestos e das imagens que, na sua integralidade, compõem a cena.

\subsection{ANÁLISE DO QUADRO BATE-PAPO: OS PARTICIPANTES}

Considerando o quadro e o programa, pode-se observar que, em geral, os quadros de Bate-papo abrem com um making off, alguns em preto e branco, outros em cores, onde entrevistados e entrevistadora preparam-se para a entrevista auxiliados por profissionais da equipe técnica. É o único quadro do programa com essa configuração/estrutura. Concomitante ao

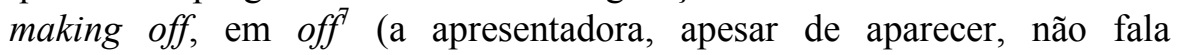
diretamente com os participantes ou para o público, o som não é revelado pela imagem), apresenta uma síntese da entrevista ou do bate-papo com o convidado do dia.

Durante a apresentação dessas imagens, em off, Laura Medina fala sobre o tema do bate-papo: "O nosso bate-papo de hoje... é sobre ansiedade. Pesquisas médicas apontam... que cerca de 5\% dos adultos sofrem com esse transtorno emocional. Quem fala sobre o assunto é o psiquiatra Cláudio Martins".

Ao finalizar o off, na tela é inserida a imagem congelada do convidado e são introduzidas suas credenciais. A apresentação das credenciais valida o saber especializado, o saber autorizado e antecipa, para o público, o grau de conhecimento dessa autoridade. O saber científico parte de um especialista da área, não necessariamente de um cientista/pesquisador ligados a Institutos de pesquisa, a Universidades, etc.

\footnotetext{
${ }^{7}$ Fala que acompanha a imagem de uma gravação, pronunciada por alguém que não aparece em cena (HERNANDES, 2006, p. 146).
} 
No quadro analisado, o convidado é um médico, reconhecido em Porto Alegre pelo trabalho desenvolvido junto ao Instituto Cyro Martins, "uma entidade de cunho científico e assistencial, tendo suas atividades direcionadas para três âmbitos: ensino, prevenção e tratamento"8.

$\mathrm{Na}$ sequência, em cenários variados (sala de estar, varandas, cafés, restaurantes), os participantes do programa, sentados, iniciam a conversa sobre o tema. Todos os quadros têm duração média de 5 minutos. A variação para mais ou para menos é de 30/40 segundos. São os rigores do tempo na TV.

No programa analisado neste artigo, o cenário é a sala de estar, ambientando a entrevista com o psiquiatra Cláudio Martins. Esses espaços, segundo Lage (2001), evitam marcas aparentes de hierarquia, como uma mesa de escritório. Apesar de o cenário ser um espaço em que as posições tornam-se aparentemente mais igualitárias, a relação entre entrevistador e entrevistado é marcada por desigualdades explícitas: o uso de terno e gravata é um dos recursos semióticos pelos quais pode ser interpretada a posição do entrevistado, o seu papel como especialista no assunto, tendo em vista sua (re)apresentação como figura pública na área de conhecimento - psiquiatria de uma entidade de cunho científico e assistencial. Isso o distancia de outros participantes, tais como os telespectadores ou a entrevistadora. Por meio das escolhas do figurino mais a combinação de outros recursos semióticos e sua posição à direita, em uma situação aparentemente confortável, revelando um estado de baixa tensão entrevistado - torna-se evidente o distanciamento social entre os participantes.

\subsection{A ORGANIZAÇÃO DO BATE-PAPO}

Cenário: Entrevistadora e entrevistado - sentados - sala de estar;

Abertura: making off; Laura Medina em off introduz a entrevista, situa o telespectador sobre o assunto; informa sobre pesquisas relacionadas ao assunto; apresenta dados e o entrevistado;

\footnotetext{
8 Informações disponíveis em: <http://www.cyromartins.com.br/app_Content/index.asp $\geq$. Acesso em 28.09.2012.
} 
Credenciais: Foto congelada com credenciais do entrevistado;

\section{Corpo da entrevista}

Início da entrevista: Laura Medina faz uma pergunta ou provoca a entrada da fala do entrevistado;

Entrada da fala do entrevistado: Resposta à provocação da entrevistadora;

Interferências da apresentadora: Respostas do entrevistado são intercaladas por inserções da fala da entrevistadora; as trocas de turno são raramente delimitadas.

Encerramento: Fechamento com a fala da entrevistadora - uma conclusão sobre o assunto discutido no Bate-papo; agradecimento ao entrevistado.

Enquadramento: A entrevistadora procura ficar "fora de cena", aparecendo pouco ou lateralmente. O entrevistado está sempre de frente para a câmera e, pelo enquadramento, fala ora com a entrevistadora, ora com os telespectadores.

Tom: No bate-papo, o tato, em termos de modulação, tende a mesclar o informal com o casual e o íntimo, pois a fala, a linguagem sonora aliada à linguagem visual (engajamento e distância) possibilitam interpretar esse quadro como uma conversa amigável que visa informar o telespectador sobre assuntos aparentemente densos - ansiedade.

$\mathrm{O}$ bate-papo parece ser muito mais uma conversa entre um especialista e uma jornalista, sobre um tema de interesse, para o público, que uma entrevista programada. Tais características se repetem e, novamente, o tom ou tato é um fator importante nessa interação.

\section{CONSIDERAÇÕES FINAIS}

O bate-papo, como um formato de entrevista, apresenta especificidades desde sua produção até sua veiculação. Há elementos que o relacionam com a entrevista temática, com características de entrevista dialogal e, em função do meio, apresenta aspectos que só a televisão, com sua linguagem e gramática, permite. Aparece como uma conversa informal, daí chamar-se bate-papo, afastando-se, muitas vezes, da entrevista 
estruturada. A noção de tato (STAM, 2010), nessa relação entrevistadoentrevistador, contribui para desenhar as representações na entrevista.

A conversação se evidencia a partir da relação entre os participantes que, em ambiente controlado, dialogam entre si, mas também dirigem-se ao público, especialmente na voz do entrevistador. Essa relação entre o saber especializado - o psiquiatra - e o telespectador é mediada pela jornalista. Tal mediação torna-se pano de fundo, nesse diálogo marcado pela conversacionalização (FAIRCLOUGH, 1995), pela informalidade e pela intimidade, esta que está relacionada com a proximidade e o grau de engajamento revelados, tanto pela linguagem sonora, quanto pela linguagem visual.

Há momentos do bate-papo em que os entrevistados falam continuamente, sem interrupções da entrevistadora, por um longo período (mais de 1'), sem que haja necessidade de perguntas ou de provocações. Esse tempo, demasiado longo se consideradas as urgências da televisão, permite o tratamento do tema com profundidade. Essa é uma característica da entrevista dialogal (LAGE, 2001).

A troca de turnos, tradicionalmente marcada por interrupções para a entrada da fala de um e a fala de outro, nesse quadro, nem sempre é bem delimitada. As falas se misturam e as interferências, na forma de contribuições e deixas para continuidade do assunto pelo entrevistador, são feitas com frequência pela entrevistadora. Os entrevistados: médicos psiquiatras explicam os transtornos emocionais: ansiedade e depressão, utilizando termos que transitam entre a linguagem técnica ou semitécnica (distúrbio, transtorno) e a linguagem cotidiana (doença).

Há momentos, no bate-papo, em que a entrevistadora intervém e procura redizer ou refazer a pergunta de outra maneira, com outras palavras, a fim de orientar o entrevistado para que ele repita a informação em linguagem mais acessível ou mais próxima do conhecimento da audiência. Em tom dialogal, em uma sala de estar, a interação face a face evidencia a necessidade de facilitar ao público a troca de informações, a partir da simulação de uma conversa de quem se preocupa com a saúde das pessoas. A repetição, estratégia inerente à televisão, no exemplo apresentado aqui, é introduzida para esclarecer termos técnicos, redizer o já 
dito, ressignificar - ou ressemiotizar, conforme utilizado por Iedema (2003, p. 41) - a fala do especialista por meio de explicações, de exemplos e de ampliação de significados dos tópicos e conceitos tratados no Bate-papo. A ressignificação "refere-se às mudanças de significado, de contexto para contexto, de prática para prática, ou de um estágio de prática para outra" (IEDEMA, 2003).

No Bate-papo, a ressignificação se efetiva na mudança de significado de um estágio de prática para outro. Dito de outro modo, no dizer e redizer do especialista, para simplificar as informações, podendo até mudar o significado da linguagem técnica para a linguagem comum, a linguagem que se aproxima daquela utilizada no cotidiano dos telespectadores. Destaca-se, aqui, a essência do discurso de popularização da ciência, o qual opera com lógicas próprias e necessita ser ressignificado, transposto para o discurso midiático. Esse, por sua vez, simplifica as informações, por meio de estratégias discursivas, recontextualizando-as (FAIRCLOUGH, 1995, 2003).

O tom da entrevista, conforme já expresso, é de conversa informal entre entrevistadora e entrevistado. Eles falam entre si, mas com a preocupação de dirigir-se aos telespectadores, explicitando os sintomas da depressão. Ampliam a discussão quando, por exemplo, abordam a diferença entre medicamentos tranquilizantes e antidepressivos. No quadro Batepapo, todos os entrevistados são especialistas e tratam o assunto desse lugar, procurando modular sua fala e ajustar seu tom, quando abordam o tema saúde, ao público para o qual falam.

\section{REFERÊNCIAS}

BAKHTIN, M. A estética da criação verbal. São Paulo: Martins Fontes, 1992. . Problemas da poética de Dostoievski. Rio de Janeiro: Forense, 2005.

FAIRCLOUGH, N. Media discourse. London: Edward Arnold, 1995. . Discurso e mudança social. Brasília: Ed. UnB, 2001. . Analysing discourse: textual analysis for social research. London: Routledge, 2003. 
GOMES, I. M. O Infotainment na televisão. In: XVIII COMPÓS: Belo Horizonte/MG, 2009. Disponível em:

$<\mathrm{http}$ ://www.compos.org.br/pagina.php?menu=8\&mmenu=0\&fcodigo $=1154>$.

HALLIDAY, M. A. K.; MATTHIESSEN, C. M. I. M. An introduction to functional grammar. London: Edward Arnold, 2004.

HERNANDES, N. A mídia e seus truques: o que jornal, revista, TV, rádio e Internet fazem para captar e manter a atenção do público. São Paulo: Contexto, 2006.

IEDEMA, R. Multimodality, resemiotisation: Extending the analysis of discourse as multi-semiotic practice. Visual Communication, v. 1, n. 2, p. 29-57, 2003. KRESS, G; van LEEUWEN, T. Reading images. Victoria: Deakin University Press, 1996.

LAGE, N. A reportagem: teoria e técnica da entrevista e pesquisa jornalística. Rio de Janeiro: Record, 2001.

MACHADO, A. A televisão levada a sério. São Paulo: SENAC/São Paulo: 2005.

NEWCOMB, H. Sobre aspectos dialógicos da comunicação de massa. In:

RIBEIRO, A. G.; SACRAMENTO, I. Mikhail Bakhtin: Linguagem, cultura e mídia. São Carlos: Pedro \& João, 2010.

O’HALLORAN, K. L. Multimodal Discourse Analysis. In: K. Hyland and B. Paltridge (Eds.) Companion to Discourse. London \& New York: Continuum (2011, in press).

PINHEIRO, N. F. A marquetização no discurso dos magazines femininos televisivos. 2004. 219 f. Tese (Doutorado em Ciências da Comunicação) Programa de Pós-graduação em Ciências da Comunicação, Universidade do Vale do Rio dos Sinos, São Leopoldo, 2004. Disponível em:

$<$ http://www.bocc.ubi.pt/_esp/autor.php?codautor=929>. Acesso em: 10 nov. 2012.

STAM, R. Bakhtin e a crítica midiática. In: Ribeiro, A. G.; SACRAMENTO, I. Mikhail Bakhtin: Linguagem, cultura e mídia. São Carlos: Pedro \& João, 2010. TAN, S. A systemic functional approach to the analysis of corporate television advertisements. Unpublished MA: National University of Singapore, 2005.

\section{Recebido em: 01/12/12. Aprovado em: 15/08/13.}

Title: The relation among participants of the Chat attraction from the TV show Vida e Saúde (RBSTV/RS)

Author: Najara Ferrari Pinheiro

Abstract: The TV show Vida e Saude on RBSTV/RS presents a segment for science popularization called "Bate-papo" (Chat), in 
which the chief-editor/presenter interviews guests while using characteristics of informal talk in the thematic and dialogical interview. In this article I discuss, based on the Critical Discourse Analysis, associated to the Multimodal Discourse Analysis and to the notion of tact, the relation among participants in that show by analyzing "Bate-papo" as an interview format, with specific practices, which involve sound, verbal and visual languages. Results show that the "Bate-papo" participants dialogue with each other while attempting to maintain an informal tone, evidenced by face to face interaction. In this tone, participants say and repeat information in order to simplify them, in a process of recontextualization that can even change meaning in the technical language when rephrased in common language, the one that is closer to that used in the viewer daily routine.

Keywords: Chat. Interview. Science popularization. Television. Recontextualization.

Título: La relación entre los participantes en la Charla del programa Vida y Salud (RBSTV/RS)

Autora: Najara Ferrari Pinheiro

Resumen: El programa Vida y Salud de la RBSTV/RS, en el proceso de popularización de la ciencia, presenta una parte denominada Charla, en la que la editora-jefe/presentadora del programa entrevista invitados combinando características de la charla informal con la de la entrevista temática y dialogal. En este artículo discuto, con base en el Análisis Crítico del Discurso, asociado al Análisis de Discurso Multimodal y a la noción de tacto, la relación entre los participantes, a partir del análisis de la charla como un formato de entrevista, con prácticas especificas que envuelven los lenguajes sonoro, verbal y visual. Los resultados muestran que en la Charla los participantes dialogan entre si, procurando mantener un tono informal, evidenciado por la interacción cara a cara. En ese tono, los participantes dicen y redicen las informaciones, con el fin de simplificarlas, en un proceso de re contextualización que puede hasta mudar el significado del lenguaje técnico para el lenguaje común, lenguaje que se aproxima de aquel utilizado en el cotidiano de los telespectadores.

Palabras-clave: Charla. Entrevista. Popularización de la ciencia. Televisión. Re contextualización. 